\title{
Circuit Topology Study for Distributed MPPT in Very Large Scale PV Power Plants
}

\author{
Damoun Ahmadi \\ Student Member, IEEE \\ The Ohio State University \\ Dreese Lab, 2015 Neil Avenue \\ Columbus, OH 43210, USA \\ damoun@ece.osu.edu
}

\author{
Seyed Akbar Mansouri \\ Student Member, IEEE \\ The Ohio State University \\ Dreese Lab, 2015 Neil Avenue \\ Columbus, OH 43210, USA \\ mansours@ece.osu.edu
}

\author{
Jin Wang \\ Member, IEEE \\ The Ohio State University \\ Dreese Lab, 2015 Neil Avenue \\ Columbus, OH 43210, USA \\ wang@ece.osu.edu
}

\begin{abstract}
In very large scale photovoltaic power plants (VLSPV), due to partial shading and PV modules mismatching, a single point MPPT is not be efficient for all PV modules. Therefore, distributed maximum power point tracking (DMPPT) can be utilized to increase output power capability by increasing the number of converter/inverter units. In this paper, a simple circuit is introduced to achieve DMPPT. Then, the limitations of DC bus voltage, total output power, duty ratio of the different converter choices are discussed. Simulation results also show that the proposed strategy can be utilized to realize seamless transition between soft start mode and steady state operation.
\end{abstract}

Keywords: DMPPT, Lagrange's Theorem, Sensitivity, Stability, VLS-PV

\section{INTRODUCTION}

Nowadays, renewable energies are being considered as promising resources to meet the continuously increasing demand of energy and to improve the reliability of electric power systems [1-3]. According to an IEA report, the world's total $\mathrm{CO}_{2}$ emissions and primary energy demand in 2030 will be twice as much as in 2000. This increasing energy consumption causes serious environmental problems such as global warming and acid rain. To resolve both energy and environmental problems, photovoltaic (PV) solar energy has become a significant and attractive candidate for green power generation in distribution networks [4-7]. However, due to PV's low energy density, to achieve the same megawatt power level as typical power plants do, the Very Large Scale PV (VLS-PV) power plants usually require hundreds acres of land and hundreds of thousands of PV modules [8].

One example of VLS-PV systems is the solar power plant at Nellis Air Force Base. In this 13.2 MW facility, 72,000 sun power PV modules are installed on 140 acres of land. Fifty-two $250 \mathrm{~kW}$ and two $100 \mathrm{~kW}$ Xantrex inverters are used to convert the $400 \mathrm{~V}$ dc from series-connected PV module groups to $60 \mathrm{~Hz}$ low voltage ac. Then, $60 \mathrm{~Hz}$ power transformers are used to connect the low voltage output from the inverters to the $12,470 \mathrm{~V}$ local distribution lines.

So far, four major megawatt circuit topologies (as shown in Fig. 1) have been proposed for VLS-PV systems [9]:

1. Centralized inverter,
2. String inverter,

3. String inverter with a team concept,

4. Multi-string inverter.

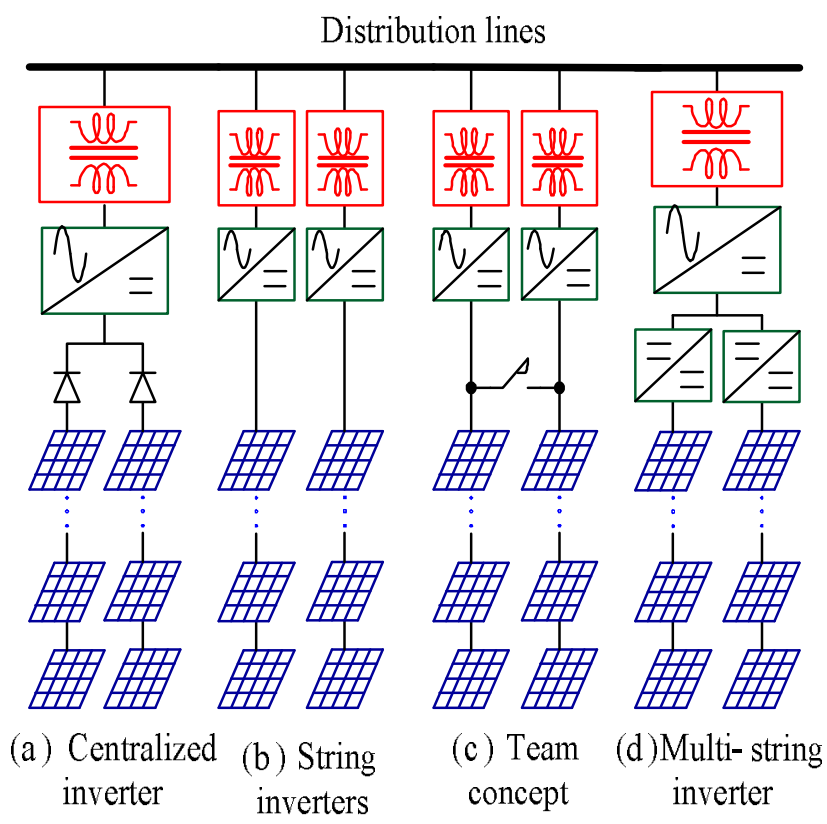

Fig. 1. Major existing megawatt circuit topologies for VLS-PV systems

The centralized inverter, as shown in Fig. 1 (a), seems to be the lowest cost solution for the megawatt PV system. However, there are several major drawbacks to this topology such as mismatch losses due to single maximum power point tracking, low upgradeability, higher power loss caused by reverse current blocking diodes, and very low continuity of service at low irradiation. In the circuit topology with string inverters, shown in Fig. 1(b), mismatch power losses are reduced and diodes between strings are eliminated. Thus, system's efficiency will be increased. The "team concept", as shown in Fig. 1 (c), utilizes a jumper switch between the strings. Therefore, the PV power plants enable to operate continuously at low irradiations. The multi-string inverter, as shown in Fig. 1 (d), has a DC/DC converter for each string that allow the integration of heterogeneous $\mathrm{PV}$ strings. This system is also upgradable to a certain extent. Since the DC/DC converters increase the number of control 
freedoms in the system, the MPPT, system protection, and ancillary services can be realized with more flexibility. The major disadvantage of this circuit topology is high cost and low reliability because of more power electronics stages are involved. So far, the most popular circuit structure is the string inverter shown in Fig. 1 (b). The Nellis PV 13.2 MW $\mathrm{PV}$ power plant is the best example.

To upgrade existing VLS-PV systems such as the one at Nellis Air Force Base to achieve more power and flexibility, DC/DC converters can be added before each inverter to form multi-string inverter as shown in Fig. 1(d). But, this solution may not be cost efficient and reliable. In this paper, a simple and cost efficient circuit is introduced. Then, Lagrange's theorem is utilized to calculate DMPPT. After that, in a case study, this circuit will be compared with other typical circuits for maximum achievable power. At the end, the sensitivity and controllability of different DC/DC converters are analyzed and compared with each others for more flexible and easier control. A seamless transition between a soft start and steady state operation is demonstrated.

\section{A SIMPLE AND COST EFFICIENT CIRCUIT TOPOLOGY FOR DMPPT}

As shown in Fig. 2, to increase the power handling of existing PV power plants with one converter a time, a DC/DC converter can be added to one string of the string inverter structure.

The following equations can be used to describe the $\mathrm{dc}$ side voltage of circuit:

$$
\begin{gathered}
V_{d c}=V_{P V .1} * f(D)+V_{P V .2} \text { and } \\
f(D)=\frac{I_{P V .1}}{I_{P V .2}},
\end{gathered}
$$

where, $f(D)$ is the transfer function of DC/DC converters. By control the current of the inverter which is connected to the grid, the total power of the inverter will be determined. Based on this power, with the specific range of modulation indexes and Vdc, the current and the related voltage of the $\mathrm{PV}_{2}$ will be controlled. Then, a desired output voltage of DC/DC converter can be calculated. Through voltage control of the $\mathrm{DC} / \mathrm{DC}$ converter, the voltage and the current of the first PV will be controlled. This idea is shown in Fig. 3.

To calculate the maximum power, based on Lagrange's theorem, (1) and (2), the following equations can be utilized as constraints:

$$
g_{1}\left(V_{P V .1}, I_{P V .1}\right)=0, g_{2}\left(V_{P V .2}, I_{P V .2}\right)=0,
$$

where, $g_{1}$ and $g_{2}$ are the dynamic equations of two PVs. As a result, the total power can be derived as follows:

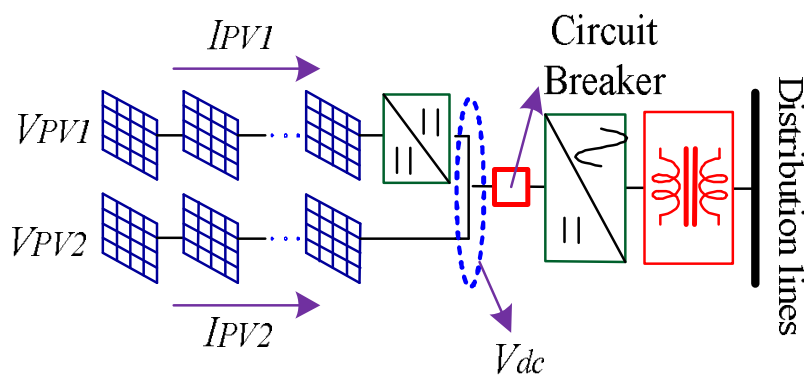

Fig. 2. The circuit topology with one DC/DC converter in VLS-PV systems

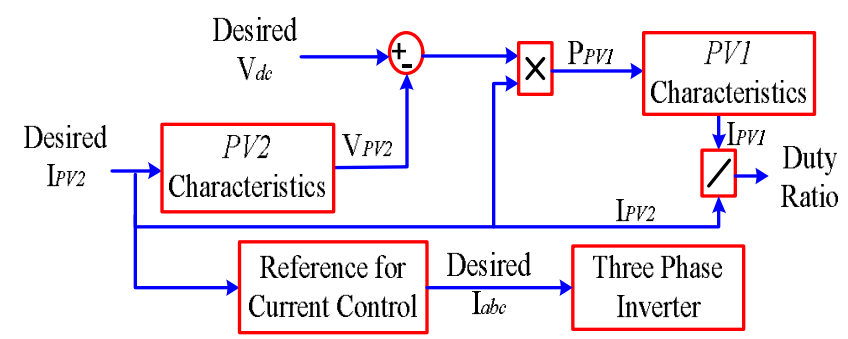

Fig. 3. Block diagram of two PV strings control with one DC/DC converter

$$
\begin{aligned}
& J=V_{p v 1} * I_{p v 1}+V_{p v 2} * I_{p v 2}+\lambda_{1} * g_{1}\left(V_{P V .1}, I_{P V .1}\right) \\
& +\lambda_{2} * g_{2}\left(V_{P V .2}, I_{P V .2}\right)+\lambda_{3} *\left(V_{d c}-V_{P V .1} * \frac{I_{P V .1}}{I_{P V .2}}-V_{P V .2}\right)
\end{aligned}
$$

In this equation, constant coefficients $\lambda_{1}, \lambda_{2}$ and $\lambda_{3}$ are used to make the derivatives of the equations equal zero. To achieve maximum power, the derivative of the total power based on the two PVs' voltages and currents should be zero:

$$
\frac{d J}{d V_{P V .1}}=0, \frac{d J}{d I_{P V .1}}=0, \frac{d J}{d V_{P V .2}}=0, \frac{d J}{d I_{P V .2}}=0
$$

By using the (1), (2), (3), and (5), the number of non-linear equations will be the same as the number of parameters. Through the use of standard numerical algorithms, such as Newton-Raphson, the PV voltage and current can be calculated and stored in a lookup table that includes irradiation and temperature. Some of the calculated results are shown in the case study part of this paper.

To implement the control algorithm for this circuit, the designed dc bus voltage should be in the reasonable range. The algorithm and modulation index that are utilized for the inverter determine the minimum voltage in the DC bus. If output voltage of inverter is directly connected to the grid, the equivalent modulation index is described by the following equation:

$$
\text { Modulation Index }(M)=\frac{\frac{V_{g r i d} * \sqrt{2}}{\sqrt{3}}}{\frac{V_{d c}}{2}},
$$


Therefore, the minimum dc voltage will be defined by the maximum modulation index:

$$
V_{d c}(\min )=\frac{2 \sqrt{2} * V_{g r i d}}{\sqrt{3} * M_{\max }} .
$$

The magnitude of dc input current for the inverter is $I_{P V 2}$. Then, based on $I_{P V 2}$ and $V_{P V 2}$, the power of $P V_{1}$ will be calculated as below:

$$
P_{P V 1}=\left(V_{d c}-V_{P V 2}\right) * I_{P V 2} .
$$

This power should not be more than $M P P T_{P V 1}$. Thus, the maximum dc voltage will be determined by the following equations:

$$
\begin{gathered}
M P P T\left(P_{1}\right)=\left(V_{d c}(\max )-V_{P V 2}\right) * I_{P V 2} \\
V_{d c}(\max )=\frac{M P P T\left(P_{1}\right)}{I_{P V 2}}+V_{P V 2}
\end{gathered}
$$

Since, the total output power is dictated by dc bus voltage and $V_{P V 2}$, if $P V_{1}$ works less than its own maximum power point, it can work on two different points with positive and negative $\frac{d P_{P V 1}}{d V_{P V 1}}$. This idea is shown in Fig. 4 . For the point " 1 " with positive derivative, at any disturbance of $V_{P V 1}$, at the same duty ratio of the $\mathrm{dc} / \mathrm{dc}$ converter, the $\mathrm{dc}$ bus will receive positive feedback. But for the point " 2 ", a possible disturbance of $V_{P V 1}$ will result in negative feedback to the dc bus. Thus a more stable working point could be achieved.

\section{CASE STUDY FOR DISTRIBUTED MAXIMUM POWER TRACKING}

To analyze maximum achievable power in the circuit, the single dc/dc converter topology is compared with two other cases: no DC/DC converter and two DC/DC converters, as shown in Fig. 5. In this comparison, two PV strings have receive different irradiations. And the total maximum power at the predefined irradiation level is $226 \mathrm{~kW}$. The results of Fig. 5(b) and (c) are listed in Tables 1 and 2 respectively. Then, in Fig. 6, the generated power for these systems is compared with each others.

As shown in the results, when two DC/DC converters are utilized, if $V_{d c}$ is chosen in the range that two converters can switch less than their maximum voltage stress, MPPT always can be achieved for both PVs [4], which is shown in Fig. 6. For the case with one DC/DC converter, in very limited range of $V_{d c}$, the total achievable power is very close to the summation of MPPT for both PVs. In the case with no
DC/DC converter, there is no compensation on PVs mismatching and the total power is decreased dramatically.

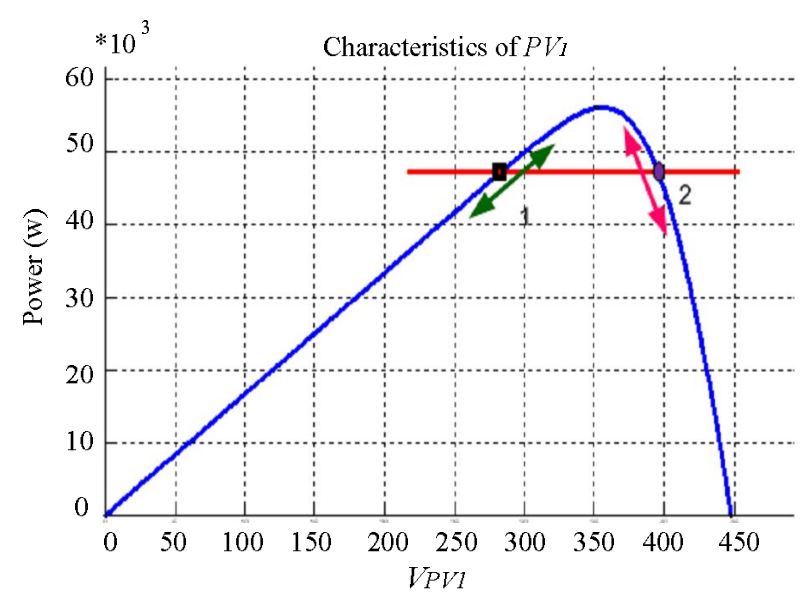

Fig. 4. Two working points for same power in first PV

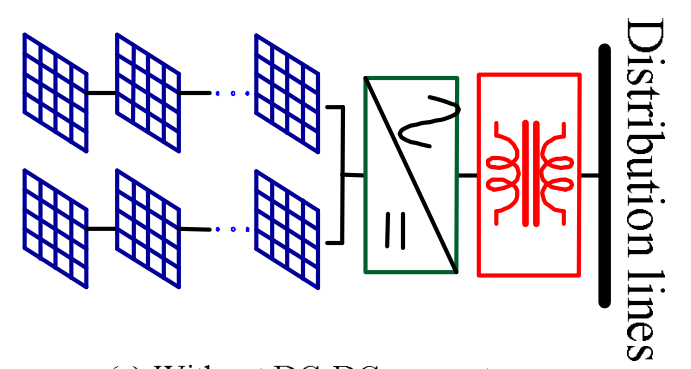

(a) Without DC-DC converter

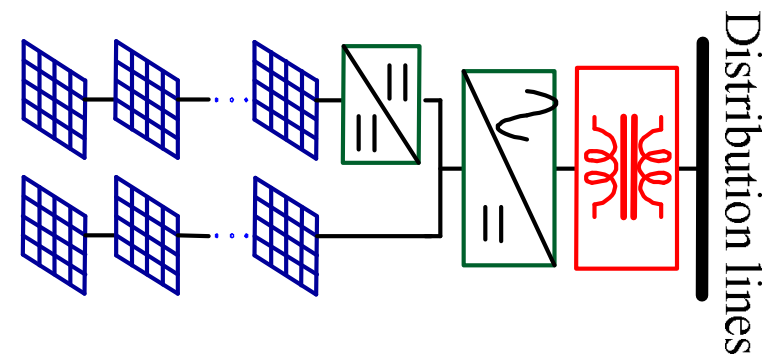

(b) With one DC-DC converter

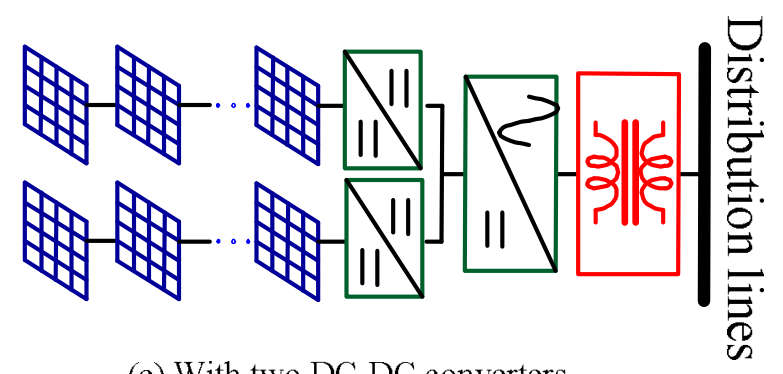

(c) With two DC-DC converters

Fig. 5. Three different circuit topologies for DMPPT in VLS-PV 
To analyze the control sensitivity, for the case study with one DC/DC converter, different transfer functions are tested. Then, the change of duty ratio for $V_{d c}$ from $600 \mathrm{~V}$ to $1000 \mathrm{~V}$ is calculated and compared with each others. The results are shown in Fig. 7. As shown in this picture, by using D/(1-D) or (1-D)/D transfer function (buck-boost converter), range of changes for duty ratio will be increased. Then, more flexibility for control and implementation of $\mathrm{DC} / \mathrm{DC}$ converter can be achieved. It should be noted that for this circuit, the current of second PV string can be higher or lower than the first one. Therefore, buck or boost converter cannot be utilized.

Table. 1: The maximum generated power for two PV strings without $\mathrm{dc} / \mathrm{dc}$ converter.

\begin{tabular}{|c|c|c|c|c|}
\hline \multirow{2}{*}{$\begin{array}{l}\text { Vdc } \\
(\mathrm{V})\end{array}$} & Vpv1(V) & Vpv2 (V) & Ipv1 (A) & \multirow{2}{*}{$\begin{array}{c}\text { Pmax (Watt) } \\
\left(* 10^{5}\right)\end{array}$} \\
\cline { 2 - 4 } & \multicolumn{3}{|c|}{$* 10^{2}$} & 1.045303 \\
\hline $\mathbf{6 0 0}$ & 0.016046 & 6.283953 & 1.666001 & 1.082900 \\
\hline $\mathbf{6 5 0}$ & 0.216046 & 6.283953 & 1.666000 & 1.166199 \\
\hline $\mathbf{7 0 0}$ & 0.716045 & 6.283954 & 1.665999 & 1.249498 \\
\hline $\mathbf{7 5 0}$ & 1.216045 & 6.283954 & 1.665997 & 1.332794 \\
\hline $\mathbf{8 0 0}$ & 1.716043 & 6.283956 & 1.665992 & 1.416034 \\
\hline $\mathbf{8 5 0}$ & 2.216019 & 6.283980 & 1.665923 & 1.498418 \\
\hline $\mathbf{9 0 0}$ & 2.715664 & 6.284335 & 1.664909 & 1.568001 \\
\hline $\mathbf{9 5 0}$ & 3.210642 & 6.289357 & 1.650527 & 1.515562 \\
\hline $\mathbf{1 0 0 0}$ & 3.664459 & 6.335540 & 1.515562 & \\
\hline
\end{tabular}

Table. 2: The maximum generated power for two PV strings with one $\mathrm{dc} / \mathrm{dc}$ converter.

\begin{tabular}{|c|c|c|c|c|c|c|}
\hline \multirow{2}{*}{$\begin{array}{l}\text { Vdc } \\
(\mathrm{V})\end{array}$} & Vpv1(V) & Vpv2 (V) & $\operatorname{Ipv1(A)}$ & Ipv2(A) & \multirow[t]{2}{*}{$f(D)$} & \multirow{2}{*}{$\begin{array}{c}\operatorname{Pmax}\left(W_{5} a t t\right) \\
\left(* 10^{5}\right)\end{array}$} \\
\hline & \multicolumn{4}{|c|}{$* 10^{2}$} & & \\
\hline 600 & 3.558665 & 4.316569 & 1.574232 & 3.327827 & 0.4730511 & 1.99669679 \\
\hline 650 & 3.558665 & 4.806462 & 1.574232 & 3.307967 & 0.4758912 & 2.15017897 \\
\hline 700 & 3.558665 & 5.258411 & 1.574232 & 3.216698 & 0.4893939 & 2.25168895 \\
\hline 750 & 3.558665 & 5.616699 & 1.574232 & 2.974655 & 0.5292152 & 2.23099140 \\
\hline 800 & 3.558665 & 5.868378 & 1.574232 & 2.628125 & 0.5989946 & 2.10250001 \\
\hline 850 & 3.558665 & 6.043501 & 1.574232 & 2.280550 & 0.6902863 & 1.93846786 \\
\hline 900 & 3.558665 & 6.168876 & 1.574232 & 1.978779 & 0.7955578 & 1.78090073 \\
\hline 950 & 3.558665 & 6.261409 & 1.574232 & 1.729816 & 0.9100577 & 1.64332559 \\
\hline 1000 & 3.558665 & 6.331636 & 1.574232 & 1.527157 & 1.03082561 & 1.52715728 \\
\hline
\end{tabular}

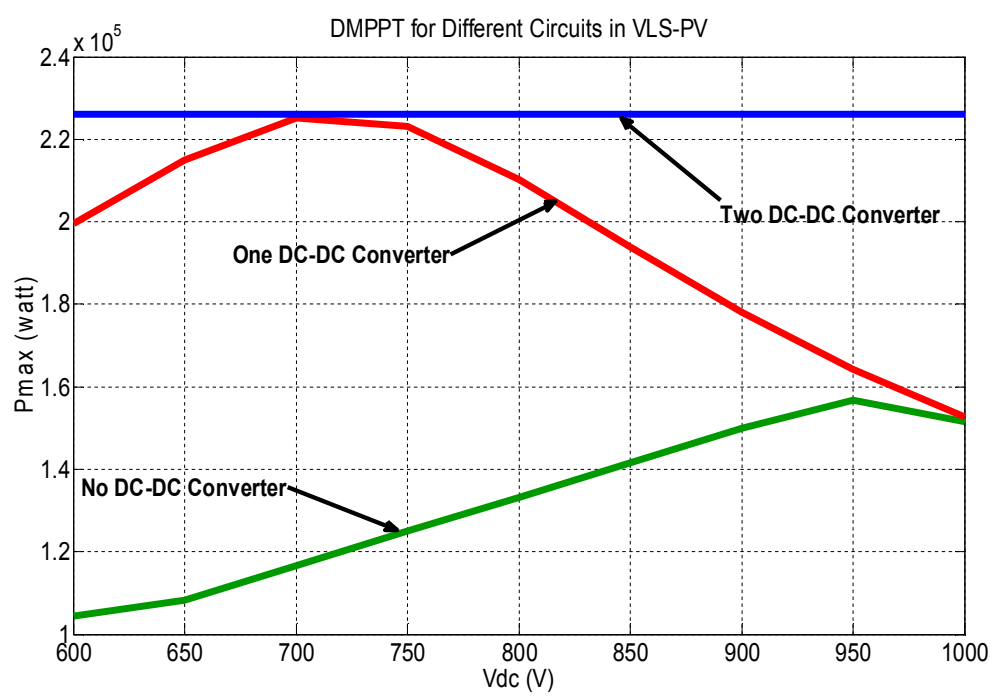

Fig. 6. Maximum achievable power for three different cases 
IV. SIMULATION RESULTS

The simulation results of circuit topology with one DC/DC converter are shown Fig. 8. The transient of total output power and dc bus voltage is shown for the case that desired dc bus voltages is set at $700 \mathrm{~V}$. The simulated output power verifies the calculated results in Table 2. The simulation results also show that with the proposed control strategy (Fig. 3), by changing the ac side current command, the one $\mathrm{dc} / \mathrm{dc}$ converter based system can start from zero output power and have seamless transition between soft start and steady state operation.

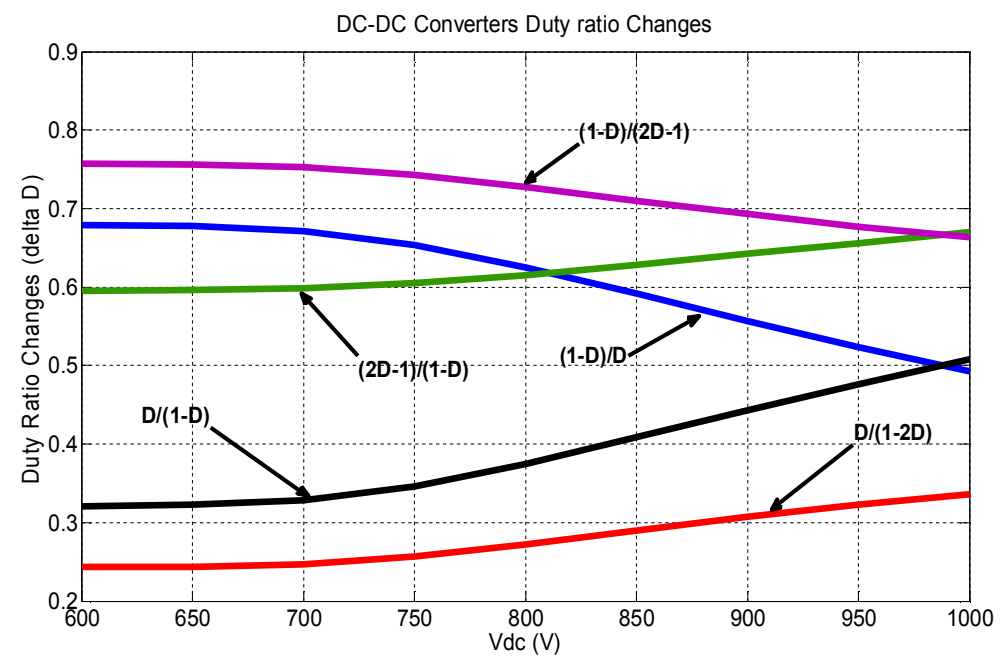

Fig. 7. Different DC/DC duty ratio changes based on dc bus voltage.

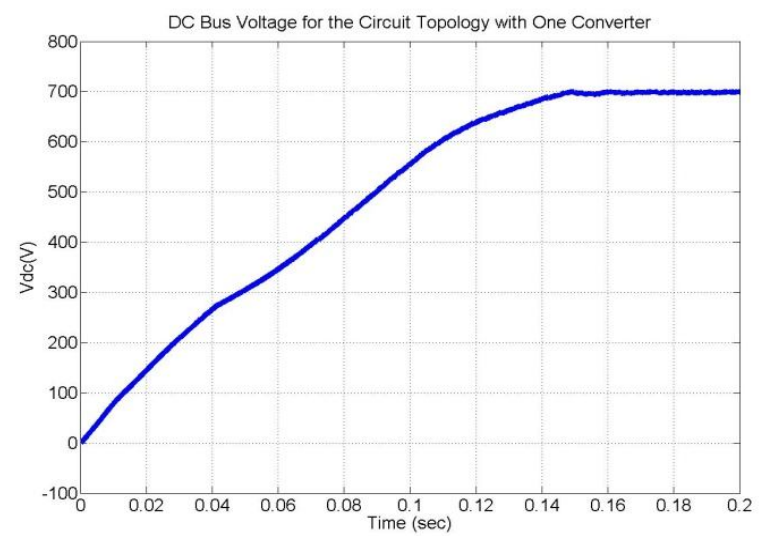

(a) Dc bus voltage control

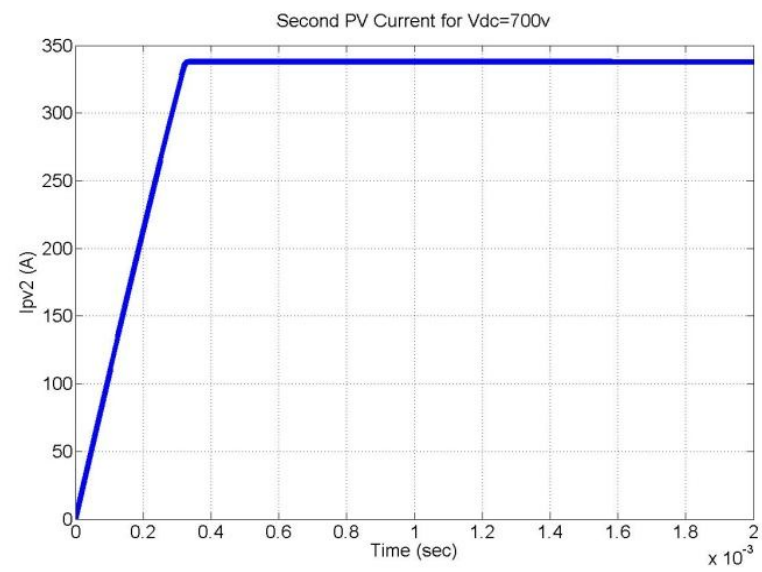

(c) $\mathrm{pv}_{2}$ output voltage

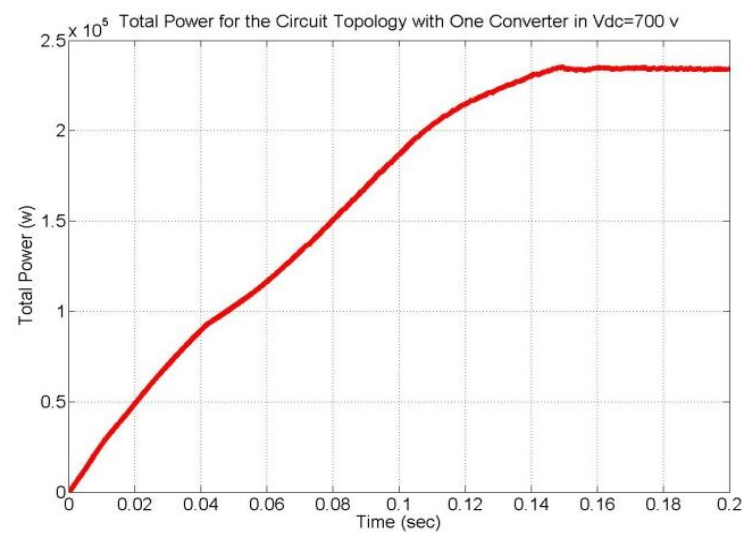

(b) Total output power

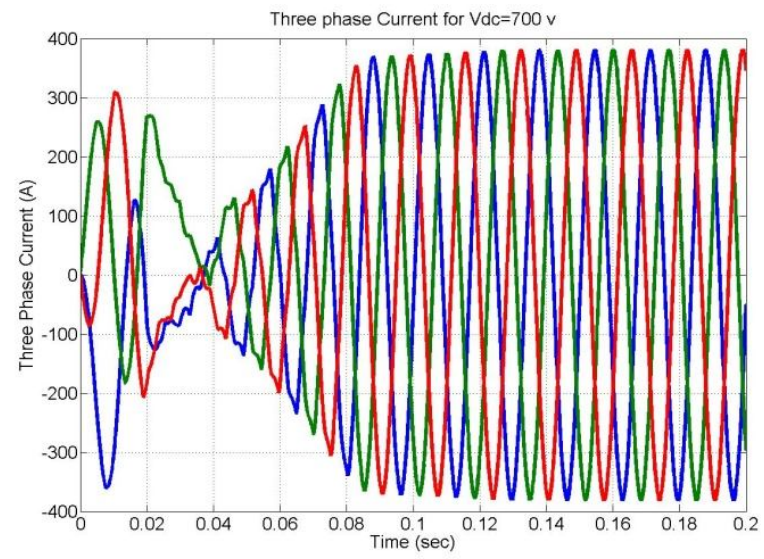

(d) ac side current

Fig. 8. Simulation results (a) Dc bus voltage control; (b) Total output power; (c) pv $v_{2}$ output voltage; (d) ac side current. 


\section{CONCLUSION}

In this paper, a single $\mathrm{DC} / \mathrm{DC}$ converter based solution is shown as an addition to the power conditioning circuit topologies for VLS PV power plants. The benefit of this circuit is that it could be used to upgrade the existing systems with one $\mathrm{dc} / \mathrm{dc}$ converter at a time. A case study is shown in this paper. The study results show that with one more $\mathrm{dc} / \mathrm{dc}$ converter, the achievable power of the system can be improved significantly. The control strategy of the overall circuit structure and the circuit selections for the added $\mathrm{DC} / \mathrm{DC}$ converter are also introduced.

\section{REFERENCES}

[1]. "A preliminary study analysis of Very Large Scale Photovoltaic Power Generation (VLS-PV) Systems", Report IEA-PVPS VI-5 1999:1, May 1999.

[2]. M. Kato, K. Komoto, K. Kichimi, T. Kurokawa, "A Sensitivity Analysis of Very Large-Scale Photovoltaic Power Generation (VLS-PV) Systems in Deserts", IEEE Conf on PV Energy Conversion, pp. 2387 - 2390, Jan 2007.

[3]. K. Kurokawa, T. Takashima, T. Hirasawa, T. Kichimi, T. Imura, T. Nishioka, H. iitsuka, N. Tashiro, "Case studies of large-scale PV systems distributed around desert area of the world", Solar Energy Materials and Solar Cells, pp.189-196, 1997.

[4]. N. Femia, G. Lisi, G. Petrone, G. Spagnuolo, and M. Vitelli, "Distributed Maximum Power Point Tracking of Photovoltaic Arrays: Novel Approach and System Analysis", IEEE Trans on Indus Elect, vol. 55, no. 7, pp. 26102621, Jul 2008.

[5]. M. M. Casaro, D. C. Martins, " Grid-connected PV system using a threephase modified dual-stage inverter", IEEE Power Elect Conf, COBEP, pp. 167-173, 2009.

[6]. M. Braun, G. Arnold, H. Laukamp, "Plugging into the Zeitgeist-Experiences of Photovoltaic Network Integration in Germany," IEEE Power and Energy Magazine, vol 7, Issue 3, pp. 63 - 76, May-Jun 2009

[7]. V. Lughi, A. M. Pavan, S. Quaia, G. Sulligoi, "Economical analysis and innovative solutions for grid connected PV plants," in Proc. International Symposium on Power Electronics, Electrical Drives, Automation and Motion,. SPEEDAM 2008 pp: 211-216, 11-13 Jun 2008.

[8]. T. Key, "Finding a bright spot-- Utility experience, challenges, and opportunities in Photovoltaic Power," IEEE Power and Energy Magazine, vol 7, Issue 3, pp. 34 - 44, May-Jun 2009.

[9]. D. Picault, B. Raison, S. Bacha, "Guidelines for evaluating grid connected PV system topologies," in Proc. IEEE International Conference on Industrial Technology, ICIT 2009. pp: 1-5, Feb. 2009. 